\title{
O POTENCIAL PRODUTIVO BRASILEIRO: UMA ANÁLISE HISTÓRICA DA PRODUÇÃO DE MILHO
}

\author{
Felipe Dalzotto Artuzo* \\ Cristian Rogério Foguesatto** \\ João Armando Dessimon Machado*** \\ Letícia de Oliveira**** \\ Ângela Rozane Leal de Souza*****
}

RESUMO: O milho é o cereal mais produzido no mundo, possuindo relevante papel no agronegócio brasileiro, como na geração de renda e emprego em todas as regiões do país. Dessa forma, o artigo tem por objetivo analisar a evolução da área cultivada, produção, produtividade e a estabilidade produtiva do milho nas diferentes regiões do Brasil. Os dados de produção, produtividade e área foram obtidos junto aos dados históricos da Companhia Nacional de Abastecimento (CONAB). Os dados analisados compreendem os anos de 1977 a 2017, sendo divididos em três períodos: i) 1977 a 1990; ii) 1991 a 2004; e iii) 2005 a 2017. A estabilidade da produtividade foi estimada pelo coeficiente de variação (CV). Os resultados destacam as mudanças que ocorreram no período, como: i) a expansão de 49,08\% da área destinada ao cultivo de milho; ii) o aumento da produção, a partir do aumento da área e da produtividade; iii) o aumento da produtividade ao longo dos três períodos, com destaque para os Estados do Sul, Centro-Oeste e Sudeste; e iv) a instabilidade da produtividade ao longo dos anos e nas diferentes regióes.

PALAVRAS-CHAVE: Agronegócio; Área cultivada; Commodity; Produtividade.

\footnotetext{
Doutor em Agronegócios pela Universidade Federal do Rio Grande do Sul. Diretor Administrativo do Instituto Brasileiro de Bioeconomia (INBBIO), Brasil. E-mail: felipeartuzo1@hotmail.com

** Doutorando em Agronegócios pela Universidade Federal do Rio Grande do Sul (UFRGS), Brasil.

*** Doutor em Economia Agroalimentar pela Universidade de Córdoba/Espanha. Docente associado da Universidade Federal do Rio Grande do Sul (UFRGS), Brasil.

***** Doutora em Agronegócios pela Universidade Federal do Rio Grande do Sul. Docente da Universidade Federal do Rio Grande do Sul (UFRGS), Brasil.

****: Doutora em Agronegócios pela Universidade Federal do Rio Grande do Sul. Professora da Universidade Federal do Rio Grande do Sul (UFRGS), Brasil.
} 


\title{
BRAZILIAN PRODUCTION POTENTIAL: A HISTORICAL ANALYSIS OF CORN PRODUCTION
}

\begin{abstract}
Corn is one of the most cultivated cereals worldwide, with a relevant role in Brazilian agribusiness, with profit and employment in all regions of the country. The evolution of cultivated area, production, productivity and corn production stableness in different region of Brazil are investigated. Data on production, productivity and area were retrieved from the historical data of the National Supply Company (CONAB), for the 1977-2017 period, divided into three periods: i) 1977 - 1990; ii) 1991 - 2004; and iii) 2005 - 2017. Production stableness was calculated by the coefficient of variation (CV). Results highlighted the changes in the period, such as i) $49.08 \%$ expansion of area for corn crop; ii) production increase brought about by increase in area and productivity; iii) increase in productivity throughout the three periods, with special reference to the southern, center-western and southeastern states; iv) unstableness in productivity throughout the years and in different regions.
\end{abstract}

KEY WORDS: Agribusiness; Cultivated area; Commodity; Productivity.

\section{INTRODUÇÃO}

O Brasil é um importante provedor de alimentos para o mundo. Detentor de diferentes paisagens e clima, o que oferece oportunidade de cultivos para uma gama de variedades de produtos agrícolas, o Brasil tornou-se um dos maiores players na produção global de alimentos, produzindo e exportando commodities agrícolas. Dessa forma, o agronegócio tem sido vital para a economia, representando cerca de um quarto (23\%) do PIB do país. O crescimento do setor nos últimos anos significa que o seu papel no aumento da produção mundial de alimentos, e na ajuda na alimentação da crescente população mundial, está se tornando cada vez mais importante. A produção agrícola aumentou significativamente. Dentre as principais commodities produzidas do Brasil, destaca-se o milho. Em 20 anos, a sua produção cresceu em 193,55\%, enquanto a área obteve acréscimo de 45,79\%. Em 2017, o Brasil produziu mais de um bilhão de toneladas de culturas agrícolas, desses, 97,84 milhões foram de milho (Companhia Nacional de Abastecimento - CONAB, 2018).

Cultivado em diferentes regiões do mundo, o milho é um dos principais 
cereais agrícolas, sendo caracterizado como produto estratégico para a segurança alimentar. Na alimentação animal, em muitos casos, é a principal matéria-prima na produção de rações, destinadas para diversos segmentos, como na avicultura, na suinocultura e na bovinocultura (ALVES; AMARAL, 2011).

Sua aplicabilidade técnica é fundamental no sistema de rotação de culturas (milho/soja), sendo cultivado em diferentes perfis de propriedades (pequenas, médias e grandes), principalmente para produção de grãos ou para silagem. Nesse caso, devido às características de alto rendimento de massa verde ha ${ }^{-1}$, relativa facilidade de fermentação em silos e boa aceitação na alimentação animal, torna-se uma cultura de preferência na produção da silagem (GOMES et al., 2002). Os rendimentos da cultura são afetados por fatores ambientais, locais e pelo nível das técnicas básicas de produção. Além disso, quando o milho é exposto em um ambiente com menor precipitação e altas temperaturas no verão, acaba por reduzir a sua produtividade (WILHELM; WORTMANN, 2004), características predominantes nas diferentes regiões do Brasil. A expansão da área destinada à cultura, em paralelo com o desenvolvimento de inovações tecnológicas e de processos, desencadeou no aumento da produtividade e, consequentemente, da produção.

No Brasil, o milho tem sido cultivado em diferentes condições de ambiente, desde regiões frias até em regiões quentes, com baixas altitudes e latitudes, gerando diferentes potenciais de produtividade. $\mathrm{O}$ estudo da dinâmica da área cultivada, da produção e da produtividade é importante para definir ações de pesquisa, desenvolvimento e de transferência de conhecimento e tecnologia entre as regiões produtoras de milho. $\mathrm{O}$ desenvolvimento de tecnologias e a geração de conhecimentos poderão exigir estudos específicos. Por exemplo, os agricultores pertencentes a regiões com condições edafoclimáticas favoráveis para a produção da commodity podem demandar pesquisas e conhecimentos destinados a potencializar a produtividade, enquanto que os agricultores pertencentes a ambientes desfavoráveis podem demandar pesquisas e conhecimentos que visem manter uma estabilidade produtiva. Assim, é fundamental conhecer o contexto da produção de milho nas diferentes regiões.

Levando em consideração os desafios e oportunidades do cultivo de milho, o artigo tem por objetivo analisar o seu histórico, nas diferentes regiões do Brasil, tendo como foco a produção, produtividade, área destinada para a cultura e a es- 
tabilidade produtiva. O conhecimento das informações obtidas auxiliará na tomada de decisão de órgãos governamentais, na criação e implementação de políticas públicas, a fim de obter acréscimos de produtividades em regiões com potencial de produção.

\subsection{PANORAMA DA CULTURA DO MILHO NO BRASIL}

O milho é uma das commodities que dominam o mercado agrícola nacional e internacional. Alguns autores caracterizam a cultura como sendo estratégica para países de alta e baixa renda, sendo destinada para o mercado nacional e internacional (SCHMITZ; SCHMITZ; MOSS, 2005; GARCIA; MATTOSO; DUARTE, 2006; RELINGER, 2010). O seu uso, na alimentação animal, representa a maior parte do consumo no mundo, principalmente para a produção de rações. Na alimentação humana, o milho é consumido a partir de seus derivados, mas pode ser consumido sem ter sido processado. Em propriedades com baixa renda, o seu consumo tem importância na subsistência, principalmente em regiões como a do semi-árido nordestino, onde o consumo é realizado de forma direta, servindo como fonte de energia diária.

O cultivo brasileiro divide-se entre primeira e segunda safra ${ }^{6}$, tornando-se um diferencial quando comparado com outros países. Em termos de produção, o milho é o segundo colocado, ficando atrás apenas da cultura da soja. Em comparação, na safra de 2016/17, o Brasil produziu cerca de 114.074 mil toneladas de soja, contra 97.842 mil toneladas de milho (CONAB, 2018).

Com a modernização da agricultura, que foi difundida como fonte de tecnologia, a partir da metade do século XX (MATOS; PESSÔA, 2011), ocorreram avanços no sistema produtivo do milho. $\mathrm{O}$ aumento da produção impactou no abastecimento do mercado nacional e no aumento das exportações (FAVRO et al., 2015). Com novas técnicas e produtos desenvolvidos a partir da década de 1960, a agricultura brasileira foi impulsionada, iniciando um movimento produtivo crescente. Esse processo representou uma nova concepção com o objetivo de alterar a base técnica de produção e elevar a produtividade (SOUZA; TEIXEIRA, 2015). Nesse sentido, o

\footnotetext{
$\overline{6}$ Também conhecida como safrinha, geralmente é semeada após a cultura de verão entre os meses de janeiro e abril. Conforme Ponciano, Souza e Rezende (2003) a segunda safra expandiu-se a partir da década de 1980, quando o Paraná adotou esse cultivo como alternativa ao plantio de trigo.
} 
aumento na produtividade de grãos envolve diversas variáveis que influenciam no incremento produtivo.

O incremento pode ser explicado pelo nível tecnológico destinado à cultura (COELHO; CRUZ; PEREIRA, 2003). O processo de manejo, a partir da era da informação, proporcionou a difusão do conhecimento e a implementação da informação pelos produtores rurais. Além disso, questões técnicas, como o plantio direto, a biotecnologia, o aumento dos investimentos em processos relacionados ao controle de pragas e doenças, a otimização de insumos agrícolas e tecnologias de precisão, possibilitaram resultados positivos (KANEKO et al., 2012; ÁVILA; GRIEBELER; BRUM, 2015; ARTUZO; FOGUESATTO; SILVA, 2017), colocando a produção do milho em outro patamar produtivo.

Esses processos de modernização e especialização dos sistemas de produção vêm aumentando a competitividade do agronegócio (ARTUZO, 2015). Entretanto, apesar do aumento da produtividade agrícola ter apresentado melhores indicadores nos últimos anos, comparando com outros países com elevado potencial de produção, a produtividade brasileira de milho ainda apresenta resultados inferiores (GASQUES et al., 2014; FAOSTAT, 2018). A produtividade média ( $\mathrm{kg} \mathrm{ha}^{-1}$ ) dos principais produtores de milho do mundo em 2017 foi: Estados Unidos, $10.960 \mathrm{~kg} \mathrm{ha}^{-1}$; Argentina, $7.442 \mathrm{~kg} \mathrm{ha}^{-1}$; China, $5.947 \mathrm{~kg} \mathrm{ha}^{-1}$; e Brasil, $5.164 \mathrm{~kg} \mathrm{ha}^{-1}$. Apesar desses resultados, a produção total de milho, em 2017, coloca o Brasil na terceira posição entre os maiores produtores do grão, com aproximadamente 80 milhões de toneladas (FAOSTAT, 2018), atrás apenas dos EUA e China, com produção de 360 milhões de toneladas e 215 milhões de toneladas, respectivamente.

\subsection{VARIABILIDADE DAS REGIÕES BRASILEIRAS: CLIMA, BIOMA E SOLOS}

A agricultura brasileira possui certas peculiaridades que a difere de outros países, principalmente pela variabilidade nas condições produtivas do território nacional. Diferente de outros países, o Brasil permite mais que um cultivo anual de uma mesma cultura. Esse fato está atribuído às condições climáticas (PATERNIANI, 2001). Segundo a classificação de Köppen (2004), o Brasil é dividido em três grandes grupos, sendo eles: (A) Clima tropical, (B) Clima árido e (C) Clima temperado. Cada 
grupo apresenta tipos e subtipos. Os grupos são formados a partir das características relacionadas à temperatura do ar e à precipitação (PEEL; FINLAYSON; MCMAHON, 2007), sendo possível um mesmo Estado fazer parte de dois grupos distintos. As relações entre o balanço hídrico, a temperatura e a umidade do ar, fazem parte do conjunto de elementos climáticos que influencia na produtividade do milho. Desse modo, cada região (até mesmo Estado) é influenciada por diferentes condições climáticas, sendo possível mais que um cultivo agrícola em um mesmo ano, ou a perda da safra em um Estado e uma supersafra em outro.

A variabilidade dos Biomas é característica do Brasil, sendo eles: o Bioma Amazônia, a Caatinga, o Cerrado, o Pantanal, a Mata Atlântica e o Pampa. Com a adoção de tecnologias, e sua difusão, a agricultura foi impulsionada para os diferentes Biomas, principalmente o do Cerrado, tornando-o um dos mais importantes do Brasil (MAROUELLI, 2003). As características de cada Bioma conferem uma potencialidade relacionada à produção. Exemplo disso é o Bioma Pampa, que possui característica que não potencializa a produção agrícola, mas o torna favorável à produção animal (NABINGER et al., 2009).

Da mesma forma, o território brasileiro se caracteriza pela variabilidade dos tipos de solos. A intensidade de interações das diferentes formas e tipos de relevos, de clima, do material de origem, da vegetação e dos organismos associados, influenciam nos processos de formação dos solos. Essa diversidade deve-se às peculiaridades do Brasil, suas potencialidades, limitações e, em grande parte, às diferenças entre regiões quanto às formas de ocupação agrícola e quanto ao uso e desenvolvimento territorial (MANZATTO; FREITAS JUNIOR; PERES, 2002).

É possível analisar um quadro sintético das paisagens brasileiras por região. Por exemplo: a região Norte do país possui característica territorial de planícies e baixos planaltos, com clima Af (segundo a classificação de Köppen), alto teor de umidade, com predominância de solos profundos, altamente intemperizados, ácidos, de baixa fertilidade e normalmente saturado por alumínio, o qual se torna tóxico para a maior parte das plantas (exemplo o milho). Essas características pressupõem uma região com baixa produtividade, sendo necessária a implementação de inovações de produto e processo para suprir as limitações.

Neste contexto, é possível identificar a importância das inovações tecnológi- 
cas e os sistemas de manejo do processo produtivo. A tecnologia tem desempenhado importante papel no desenvolvimento agrícola, sendo possível cultivar plantas em áreas que até então eram impróprias para o seu cultivo (VALOIS, 2001). Com a tecnologia, aliado ao conhecimento do manejo, plantas foram projetadas para sobreviverem em condições climáticas para as quais antes não estavam adaptadas. $\mathrm{O}$ milho, por exemplo, requer fatores edafoclimáticos (solo e clima) ideais para o seu pleno desenvolvimento, como: solos ricos em nutrientes, temperatura e precipitação (EMBRAPA, 2002). Assim, considerando o Brasil como um país continental, no qual há variabilidade de fatores que impactam no desenvolvimento das culturas, torna-se fundamental analisar, ao longo dos anos, como tem ocorrido a expansão das áreas, o aumento da produção, da produtividade e a estabilidade produtiva, levando em consideração as peculiaridades de cada região.

\section{METODOLOGIA}

\subsection{DESCRIÇÃO DO ESTUDO}

A área cultivada de milho, a produção e a produtividade são tidos como variáveis do estudo. Os dados anuais das variáveis, no período de 1977 a 2017, foram obtidos junto à série histórica divulgada pela Companhia Nacional de Abastecimento (CONAB, 2018). Considera-se na análise as regiões Centro-Oeste, Nordeste, Norte, Sudeste e Sul, sendo elas compostas pelos Estados descritos no Quadro 1.

Quadro 1. Estados pertencentes a cada região

\begin{tabular}{|l|l|}
\hline \multicolumn{1}{|c|}{ Regiões } & \multicolumn{1}{c|}{ Estados } \\
\hline Centro-Oeste & Distrito Federal, Goiás, Mato Grosso e Mato Grosso do Sul \\
\hline Nordeste & $\begin{array}{l}\text { Alagoas, Bahia, Ceará, Maranhão, Paraíba, Pernambuco, Piauí, Rio Grande do } \\
\text { Norte e Sergipe }\end{array}$ \\
\hline Norte & Acre, Amapá, Amazonas, Pará, Rondônia, Roraima e Tocantins \\
\hline Sudeste & Espírito Santo, Minas Gerais, Rio de Janeiro e São Paulo \\
\hline Sul & Paraná, Santa Catarina e Rio Grande do Sul \\
\hline
\end{tabular}


As variáveis foram divididas em três períodos, a fim de reduzir os erros quanto à análise de um período único de 41 anos, sendo possível avaliar as mudanças ao longo dos anos. Os períodos foram divididos conforme os picos de oscilações das séries históricas. Assim, os períodos divididos compreendem: i) safra de 1977 a 1990; ii) safra de 1991 a 2004; e iii) safra de 2005 a 2017.

\subsection{ANÁLISE DOS DADOS}

A fim de analisar o comportamento das variáveis entre as regiões e entre os períodos, os dados foram submetidos à análise de variância (a), seguido pelo teste de média de Scheffé (b) a 5\% de probabilidade de erro. A análise da variância permite identificar as diferenças significativas entre os grupos. O teste de média identifica a ordem dos grupos, caso esses apresentem diferença significativa a partir da análise de variância (COOPER; SCHINDLER, 2003).

$$
F_{(g-1, n-g)}=\frac{Q M T r}{Q M R}
$$

Onde:

QMTr = quadrado médio de tratamento;

$\mathrm{QMR}=$ quadrado médio de resíduos;

$\mathrm{g}=$ número de grupos; $\mathrm{e}$

$\mathrm{n}=$ tamanho da amostra.

$$
D M S_{\text {Scheffé }}=\sqrt{(t-1) \times F \times V}(\mathrm{~b})
$$

Onde:

$\mathrm{t}=$ número de tratamentos;

$\mathrm{F}=$ valor de $\mathrm{F}$ tabelado para (t-1) e GL. (graus de liberdade); e

$\mathrm{V}=$ variância do contraste.

Para estimar a estabilidade da produtividade do milho nas diferentes regiões e períodos, foi calculado o coeficiente de variação (CV). Adicionalmente, realizou- 
-se análise de correlação entre o $\mathrm{CV}$ da produtividade e a produtividade média das regiões. As análises foram realizadas com auxílio de planilhas Excel e softwares Sigmaplot 11.0 e Statistical Package for the Social Sciences - SPSS v. 20.

\section{RESULTADOS E DISCUSSÃO}

\subsection{EXPANSÃO DA ÁREA DE CULTIVO DO MILHO}

O cultivo do milho apresenta dispersão geográfica, sendo produzido em todas as regiões do Brasil. Esse fato, ao mesmo tempo que demonstra a importância social e econômica da cultura, fornece evidências das variações nas formas de produção que são determinadas por condições climáticas e de solo, disponibilidade de infraestrutura de produção e mercado, e de fatores sociais e econômicos ligados aos produtores e ao mercado. A análise agregada da realidade, por vezes, não revela detalhes circunscritos a situações geográficas particulares, mas podem ser de importância fundamental para o desenvolvimento da cultura. Entender a alocação geográfica do milho pressupõe a possibilidade de ações para induzir a maximização da produção.

A área brasileira destinada à produção de milho, ao longo dos anos, apresentou consideráveis avanços, passando de 11.797,3 mil ha, na safra de 1976/77, para 17.591,4 mil ha, na safra de 2016/17, incremento de aproximadamente 49,11\%. Esse resultado coloca o Brasil como o terceiro país com a maior área destinada para a cultura (FAOSTAT, 2018). Entre as regiões do país, o Centro-Oeste apresentou resultado de maior destaque, principalmente após a safra 2005/06 (Figura 1). Com a intensificação populacional, desde meados dos anos 1940, com a chamada "Marcha para o Oeste" e o desenvolvimento econômico promovido a partir da intensa política de expansão das fronteiras agrícolas nas áreas de Cerrado, o Centro-Oeste aumentou a área de cultivo de forma mais expressiva que as demais regiões (PEDROSO, 2004). Programas específicos desenvolvidos na região incentivaram o aumento da área, principalmente o POLOCENTRO (Programa de Desenvolvimento dos Cerrados) e o PRODECER (Programa de Cooperação Nipo-Brasileira para o Desenvolvimento dos Cerrados). 


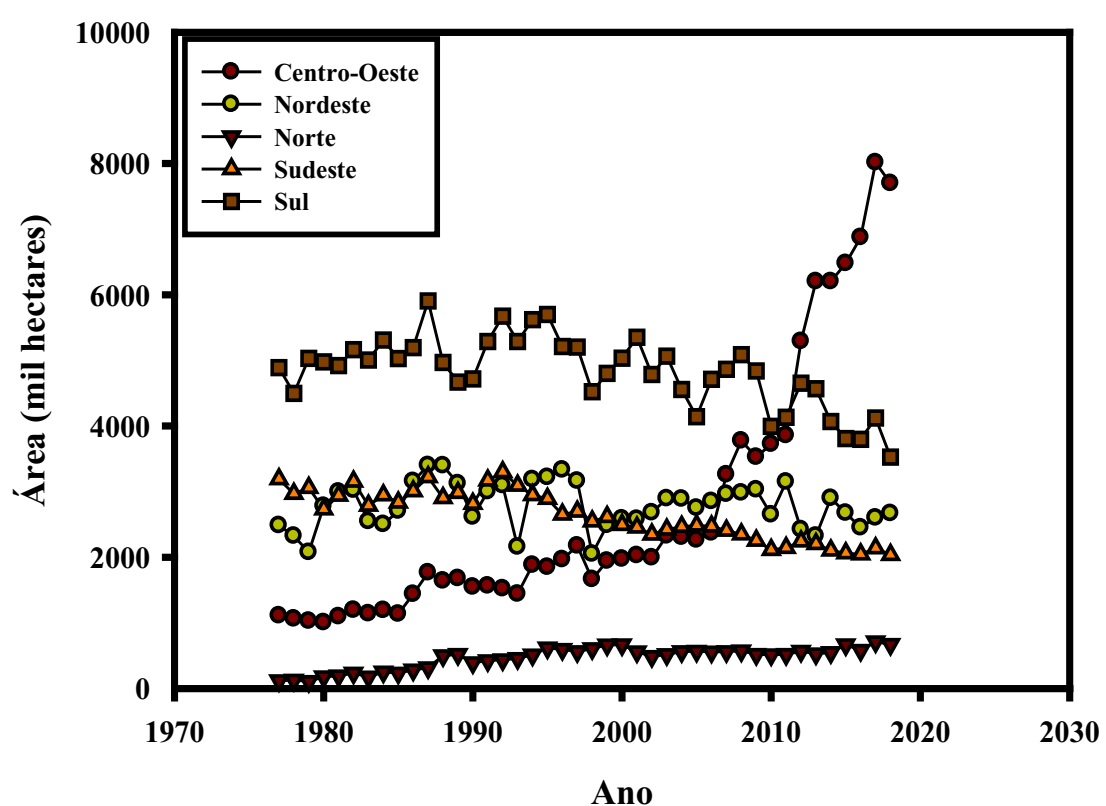

Figura 1. Série histórica da área plantada de milho dividida entre as regiões brasileiras Fonte: Elaborada pelos autores com base em dados da CONAB (2018).

A perspectiva de clima favorável também influenciou a expansão da área agrícola para a produção de milho. Segundo o Instituto Mato-Grossense de Economia Agropecuária (IMEA, 2015), parte dos produtores agrícolas do Centro-Oeste, principalmente do Mato Grosso, são na essência produtores de soja, o que é um fator determinante para o aumento da área do milho, visto que ambas as culturas utilizam, praticamente, os mesmos maquinários e implementos agrícolas.

O Mato Grosso passou a ser o Estado com a maior área de milho, ocupando a primeira posição entre os Estados com a maior área de cultivo de milho safrinha, com 3.654 mil ha em 2016/17. Na região Norte, o incremento da área apresentou resultados crescentes e expressivos, com aumento de 290\%, especialmente a partir da década de 1980. Na região Nordeste, o aumento da área foi de 7\%, o menor quando comparada com as demais regiões. Historicamente, a região Sul foi a região com maior área cultivada, posição que se manteve no primeiro e segundo período. 
Entretanto, no terceiro período, equiparou-se com a região Centro-Oeste. Nesse sentido, apesar da área ter expandido em 14\% no Paraná, desde a década de 1970, os Estados de Santa Catarina e Rio Grande do Sul obtiveram redução de 38,7\% e $56,2 \%$, respectivamente.

A oscilação da área cultivada, variando em cada região, ocorreu a partir de diversos fatores, como: i) as condições edafoclimáticas (ALBUQUERQUE et al., 2013); ii) a percepção de riscos dos produtores (ASSEFA et al., 2017); e iii) questões macroeconômica e microeconômica (ASSEFA et al., 2017; VILLORIA; CHEN, 2018). A partir disso, ocorreram transformações relacionadas ao panorama da "área cultivada de milho" no cenário brasileiro (Tabela 1).

Tabela 1. Grupos homogêneos da área de milho cultivada no Brasil

(Continua)

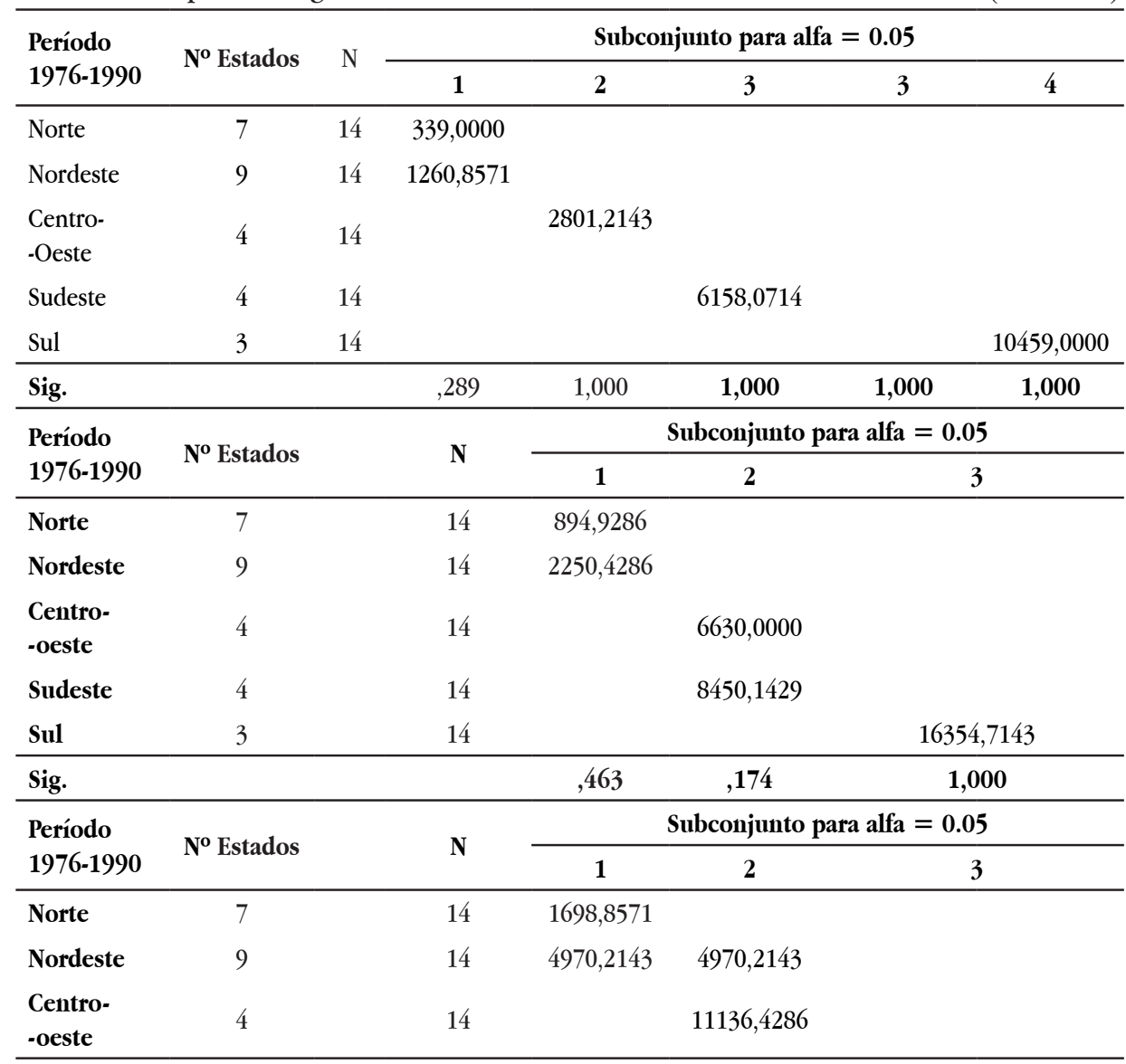


(Conclusão)

\begin{tabular}{lccccc}
\hline \multirow{2}{*}{$\begin{array}{l}\text { Período } \\
\mathbf{1 9 7 6 - 1 9 9 0}\end{array}$} & \multirow{2}{*}{$\mathbf{N}^{\mathbf{0}}$ Estados } & N & \multicolumn{3}{c}{ Subconjunto para alfa $=\mathbf{0 . 0 5}$} \\
\cline { 4 - 6 } & & & $\mathbf{1}$ & $\mathbf{2}$ & $\mathbf{3}$ \\
\hline Sudeste & 3 & 14 & & & 22496,3571 \\
Sul & 4 & 14 & & & $\mathbf{2 5 8 9 6 , 6 4 2 9}$ \\
\hline Sig. & & &, 766 & $\mathbf{1 7 7}$ & $\mathbf{7 3 9}$ \\
\hline
\end{tabular}

Nota: Regiões, por período, submetidos à análise de variância a nível de significância de $\mathrm{p}<0,01$. Teste de Scheffé a nível de $\mathrm{p}<0,005$. São exibidas as médias para os grupos em subconjuntos homogêneos.

Fonte: Elaborada pelos autores com base em dados da CONAB (2018).

A região Sul deixou de ter hegemonia na área de cultivo, principalmente quando analisados os três períodos. No primeiro e segundo períodos, os Estados do Sul se destacaram na área de cultivo, sendo superior às demais regiões. Já no último período analisado, a região Centro-Oeste equiparou-se a sua área com a região Sul, não havendo diferenças significativas. Esse fato demonstra a mudança no desenho produtivo da cultura nas diferentes regiões do Brasil.

\subsection{EXPANSÃO DA PRODUÇÃO DE MILHO E O SEU REFLEXO NA PRODUTIVIDADE}

Pesquisas internacionais têm se dedicado a estudar a evolução dos indicadores produtivos do milho e à sua análise econômica, a fim de obter estimativas empíricas sobre o histórico da produção agrícola do cereal, dos níveis de produtividade e dos resultados das safras. No cenário brasileiro, a produção de milho aumentou ao longo dos anos, passando de 19.256 mil toneladas, na safra de 1976/77, para 97.842 mil toneladas, na safra de 2016/17, resultando em um incremento de 408,13\%. Parte desse resultado deve-se à região Centro-Oeste, a partir da expansão da área e pelo investimento na produção agrícola (Figura 2). Além disso, o mercado interno exposto a maior competição com o milho importado induziu os produtores brasileiros a buscar aumentos contínuos de produtividade, o que ocasionou crescimento na produção nacional (CALDARELLI; BACCHI, 2012). 


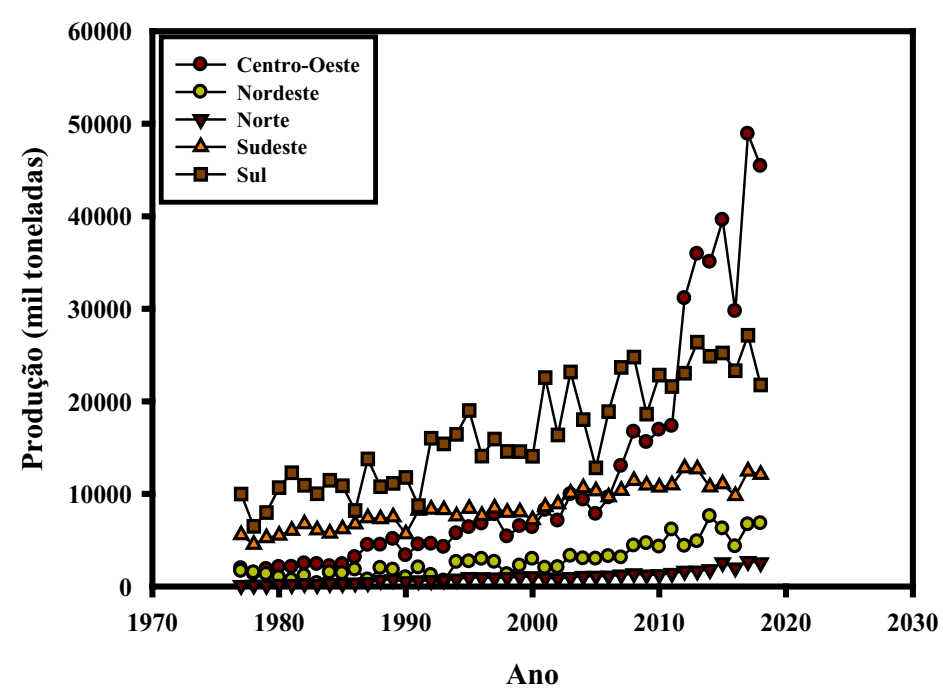

Figura 2. Série histórica da produção de milho dividida entre as regióes brasileiras Fonte: Elaborada pelos autores com base em dados da CONAB (2018).

A predominância da produção de milho, que estava concentrada na região Sul, passou a ser concentrada, também, no Centro-Oeste, principalmente a partir das safras em que houve maior expansão na área de cultivo nos Estados que compõem a região (Tabela 2). Por exemplo, no período de 2016/17, o Mato Grosso, com produção de $28.867,4$ mil toneladas, foi o Estado que obteve a maior produção de milho, posto que ocupa desde a safra de 2012/13, quando ultrapassou a produção paranaense. 
Tabela 2. Grupos homogêneos da produção de milho no Brasil

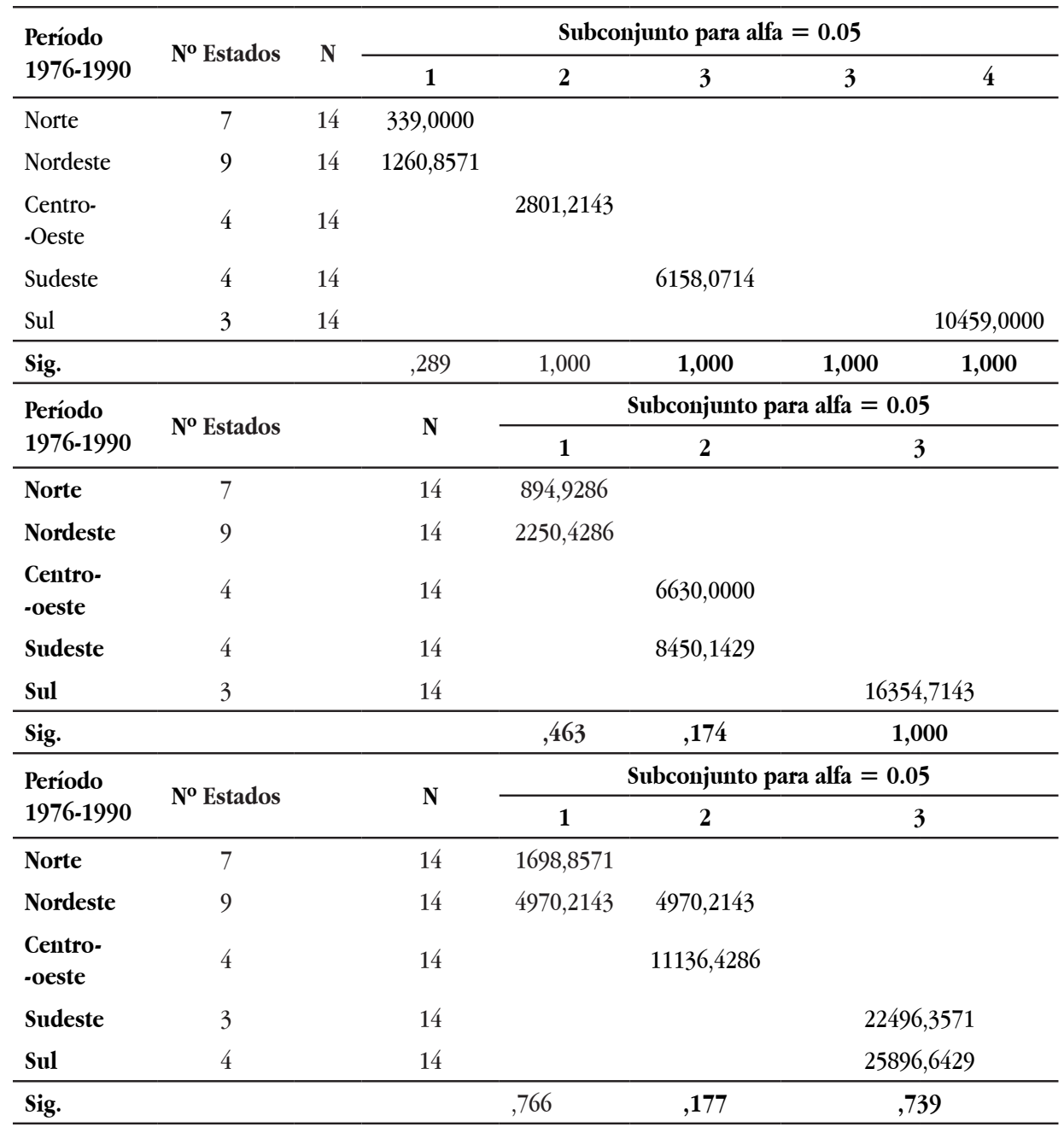

Nota: Regiões, por período, submetidos à análise de variância a nível de significância de $\mathrm{p}<0,01$. Teste de Scheffé a nível de $\mathrm{p}<0,005$. São exibidas as médias para os grupos em subconjuntos homogêneos.

Fonte: Elaborada pelos autores com base em dados da CONAB (2018).

A situação proeminente é a do Nordeste e a do Norte. O Nordeste predomina o domínio natural da caatinga, que, por questões climáticas, apresenta irregularidade pluviométrica (ALMEIDA et al., 2018) e, por consequência, baixo rendimento da cultura. A região Norte, domínio natural da Amazônia, também apresenta carac- 
terísticas ambientais que limitam a produção de milho. Nas demais regiões, as limitações podem ser de outra ordem que não a natural, por exemplo, as condições de mercado ou situações sociais, nas quais prevalece a agricultura tradicional. Apensar da dispersão geográfica, os dados oficiais revelam uma concentração da produção na região Sul e Centro-Oeste. As alterações na distribuição da produção por região, entre os anos, podem ser creditadas a fenômenos climáticos que ocorrem ou a situações conjunturais que estimulam ou desestimulam a produção, que devem ser estudados de forma específica e com profundidade.

As demais regiões também apresentaram aumento na produção, sendo que, apesar da menor proporção em termos de escala, essa alavancagem foi considerável. $\mathrm{Na}$ série histórica, as regiões Sudeste, Nordeste e Norte apresentaram crescimento produtivo, respectivamente, de $123,60 \%, 306,07 \%$ e 2191,52\%. Nesse âmbito, os Estados do Norte, que na safra 1976/77 produziam 118 mil toneladas, obtiveram incremento na produção de 2.704 mil toneladas, na safra 2016/17. Esses avanços contribuíram, e contribuem, para o abastecimento interno e para negociações no mercado internacional (FAVRO et al., 2015). O histórico do aumento da produção de milho está relacionado com a produtividade, mesmo considerando o aumento na área cultivada. Ao longo dos anos, houve aumento da produtividade, diferenciando entre as regiões (Tabela 3). Dessa maneira, as técnicas agrícolas voltadas para a cultura de milho evoluíram, quando comparadas com as técnicas agrícolas de décadas passadas, sendo fundamental para o aumento da produtividade. 
Tabela 3. Grupos homogêneos da produtividade de milho no Brasil

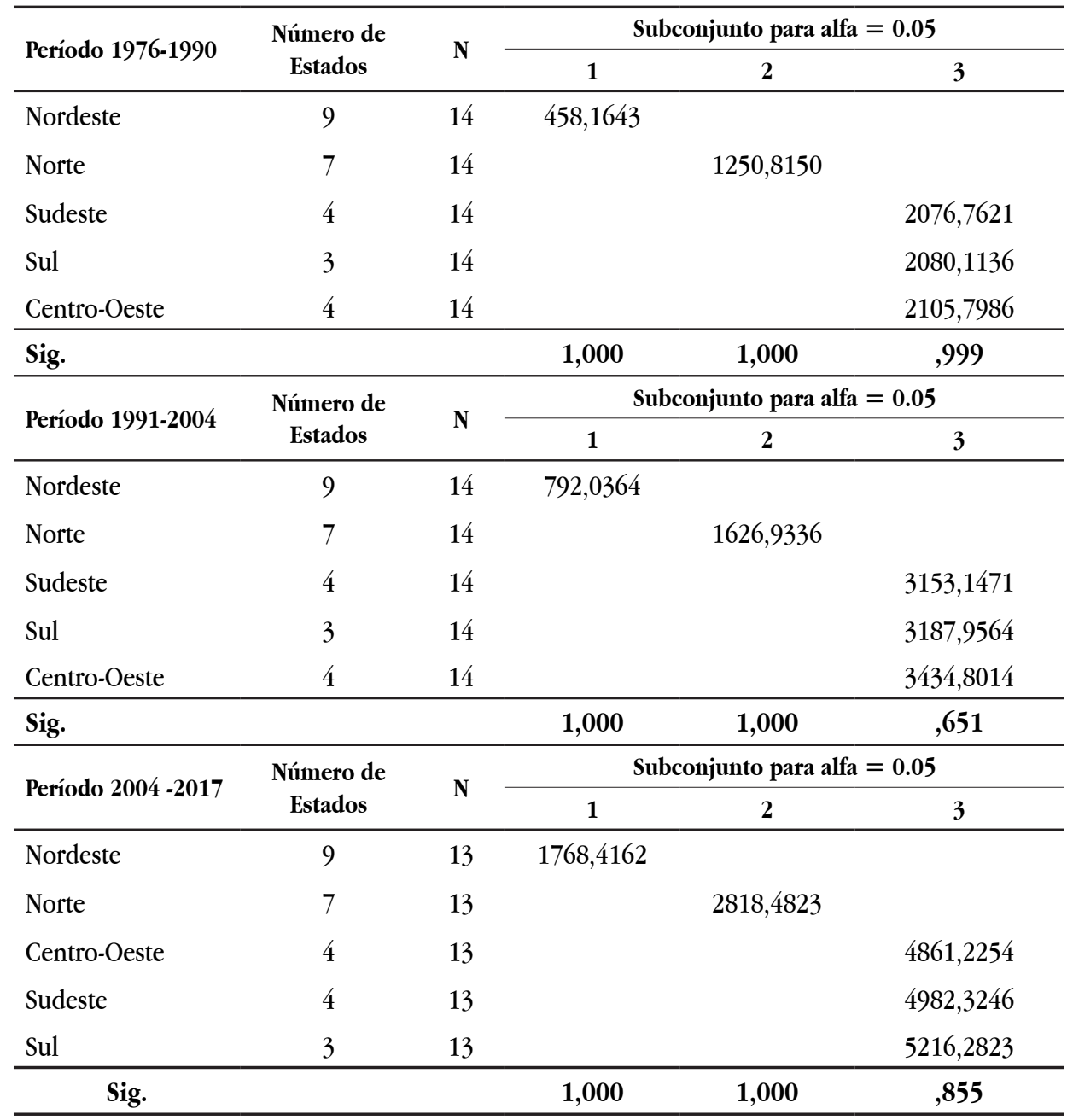

Nota: Regiões, por período, submetidos à análise de variância a nível de significância de $\mathrm{p}<0,01$. Teste de Scheffé a nível de $\mathrm{p}<0,005$. São exibidas as médias para os grupos em subconjuntos homogêneos.

Fonte: Elaborada pelos autores com base em dados da CONAB (2018).

De maneira semelhante aos resultados históricos da área de cultivo, as regiões Sudeste e Centro-Oeste obtiveram alto incremento de produção, quando analisados os três períodos conjuntamente. Mas, quando analisado por período, a região Sul sempre esteve entre as regiões com alta produção e produtividade. No primeiro 
e segundo períodos, despontou como a região que apresentou a maior produção. Sendo que no terceiro período foi equiparado com a região Centro-Oeste. Esse fato, além do relacionado à área, está atribuído a outros fatores, como, por exemplo, a modificação nas diferentes etapas produtivas, o manejo, por meio do preparo dos solos, adubação, sementes geneticamente modificadas (com alto potencial produtivo), época e métodos de semeadura, controle de plantas daninhas, pragas, doenças e tecnologias de colheita, que possibilitaram o incremento da produção.

Além disso, no último período de análise, pode-se incluir a adoção de ferramentas de precisão, que possibilitou o aumento na eficiência do uso de fertilizantes agrícolas, o que impactou, e impacta, de forma positiva no desenvolvimento de plantas e, por consequência, na sua produção (ARTUZO, 2015; MOLIN; AMARAL; COLAÇO, 2015). Motivo este também lembrado por Nogara Neto et al. (2011), em que demonstraram o aumento de rendimento do milho a partir da adoção de ferramentas de precisão. Os resultados históricos apontam para o incremento produtivo em todas as regiões brasileiras, obtendo aumento de $240,8 \%$ na produtividade nacional (entre as safras de 1976/77 e 2016/17) (Figura 3).

Embora a produtividade seja apenas um medidor parcial de desempenho que reflete, principalmente, a tecnologia de produção, pode-se observar que o rendimento médio nacional tenha ficado acima de $5.000 \mathrm{~kg} \mathrm{ha}^{-1}$, inclinando a uma média de $7.000 \mathrm{~kg} \mathrm{ha}^{-1} \mathrm{em}$ algumas regiões. Comparativamente a outros países, o Brasil possui potencial para maximizar sua produção, tendo em vista que a sua produtividade média é menor do que países como a Argentina (7.442 kg ha-1), a China (5.947 $\mathrm{kg} \mathrm{ha}^{-1}$ ) e os EUA (10.960 $\mathrm{kg} \mathrm{ha}^{-1}$ ) (FAOSTAT, 2018). 

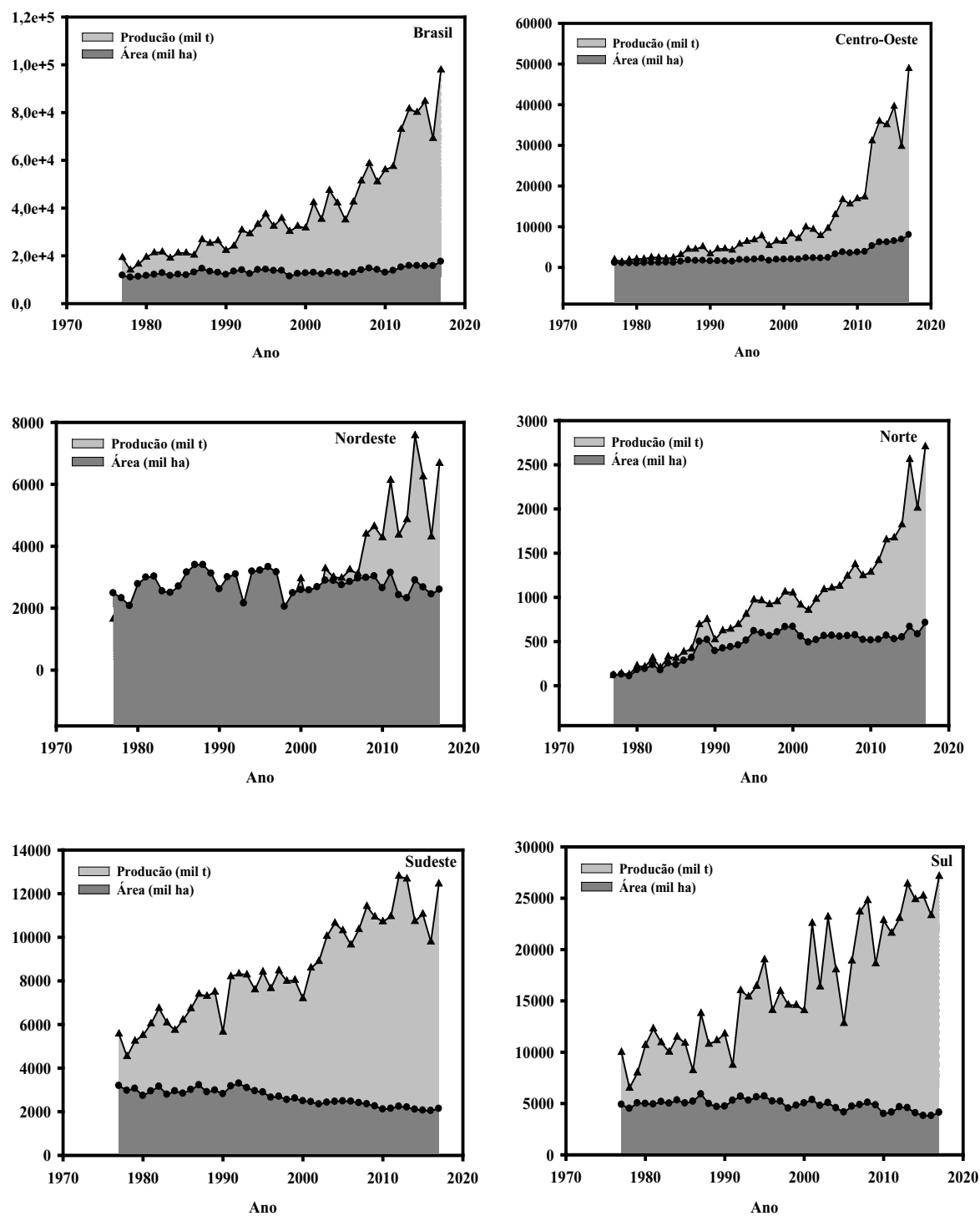

Figura 3. Série histórica da produção e área cultivada de milho nas diferentes regiões brasileiras e no Brasil.

Fonte: Elaborada pelos autores com base em dados da CONAB (2018). 
No que se refere ao Brasil, a região Nordeste apresentou o maior aumento de produtividade, com incremento de $287,97 \%$, seguida pelo Norte $(282,45 \%)$, Centro-Oeste (249,34\%), Sudeste (233,58\%) e Sul (222,49\%). Contudo, os Estados do Norte e do Nordeste ainda apresentam os menores resultados de produtividade. Com isso, percebe-se a heterogeneidade da produtividade brasileira, sendo que a variabilidade temporal é um dos fatores que limitam o incremento da produtividade média ao longo do tempo de uma dada região (Figura 4). Os Estados do Amapá, Ceará, Rio Grande do Norte, Paraíba e Pernambuco apresentaram menores resultados. Por outro lado, a região Sul, Sudeste e o Centro-Oeste destacam-se como os mais produtivos (em termos de produção por área). Nessa óptica, Santa Catarina e o Distrito Federal possuem as produtividades mais elevadas, com, respectivamente, 7.750 e $8.300 \mathrm{~kg} \mathrm{ha}^{-1}$.
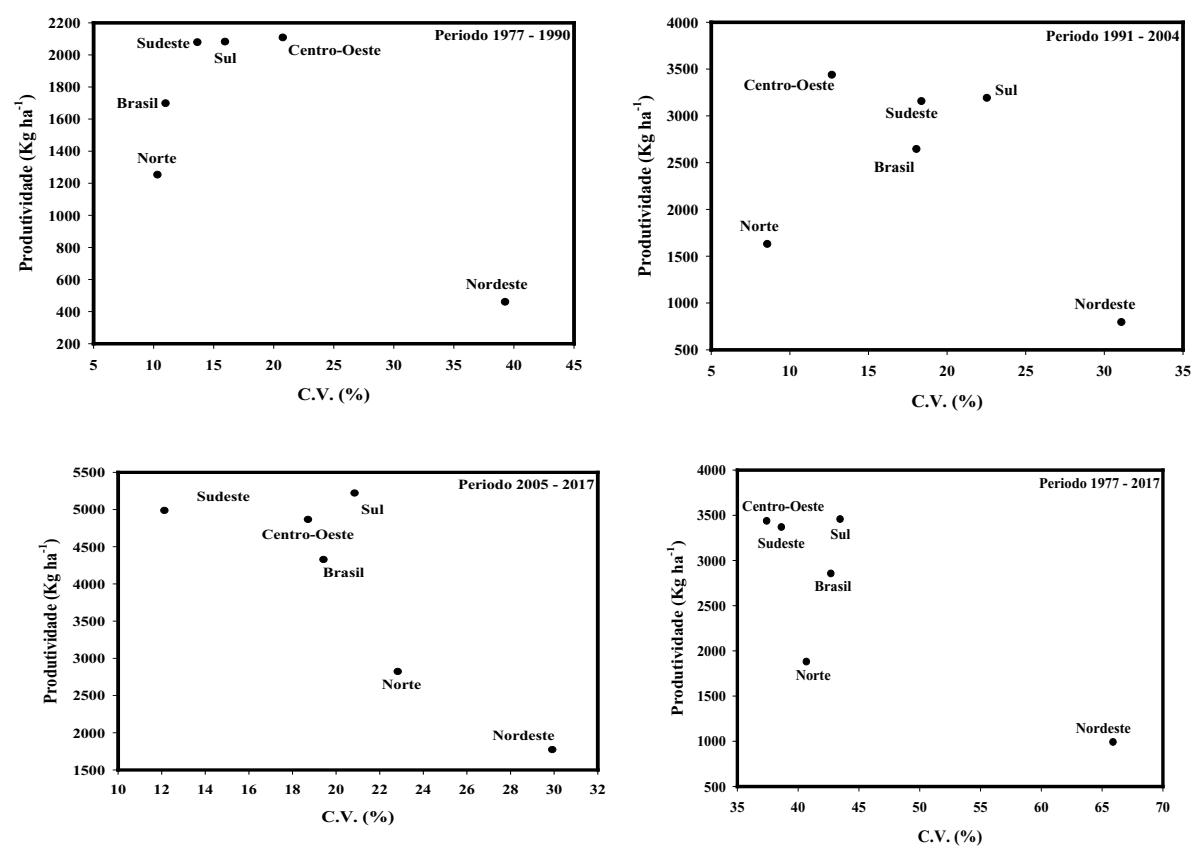

Figura 4. Relação entre a produtividade e o coeficiente de variação (C. V.) da produtividade nas regiões, nos diferentes períodos. 
A variabilidade pluviométrica entre as regiões é fator que afeta a produtividade do milho. A cultura é altamente exigente em termos de disponibilidade de água (GONG et al., 2015), que é um dos aspectos chave para a sua produção. Quantidade e distribuição de chuva são geralmente os principais fatores de produtividade que influenciam na variabilidade sob condições de sequeiro (BERGAMASCHI et al., 2004; ARAUS et al., 2012). Estudos ecofisiológicos demonstraram como a seca afeta o rendimento de diferentes formas, dependendo do estágio da cultura. Durante o estabelecimento, a seca pode reduzir a germinação das plantas; enquanto o estresse hídrico, durante a expansão da área foliar, reduz a sua área e a interceptação da radiação solar (YAN et al., 2016). Os estágios da cultura do pendoamento ao início do enchimento de grãos são críticos para o rendimento do milho (ZINSELMEIER et al., 1995). Finalmente, durante o período de enchimento de grãos, o déficit hídrico reduz a oferta de assimilados, levando a perdas no peso dos grãos e, por consequência, na redução da produtividade (ARAUS et al., 2012).

Apesar da discrepância produtiva entre as regiões, principalmente na região do semiárido nordestino, que apresenta menores índices de produtividade, por frequentes períodos de seca, o aumento da produtividade tornou o país competitivo na produção de milho. Esse cenário coloca o Brasil entre os países com maiores incrementos produtivos no segmento agrícola (GASQUES et al., 2012). Os resultados evidenciam a importância da produção brasileira de milho, sua realocação entre as regiões e a possibilidade de investimentos em regiões nas quais poderiam apresentar melhores resultados produtivos, que, até então, se mostram ineficientes. Ressalta-se que a realidade da produção de milho no Brasil pode ser analisada a partir de dois pontos de vista: i) há um segmento de produtores que têm no milho um produto de mercado, que procura cultivá-lo com alta tecnologia, obtendo altas produtividades; e ii) há outro grupo que tem no milho um insumo para outras atividades fins, atividade de apoio ou de subsistência, onde não é aplicada a melhor tecnologia, sendo obtidos rendimentos considerados baixos. A dimensão relativa de cada um desses grupos determina o nível médio de desenvolvimento da cultura no Brasil. 


\section{CONCLUSÃO}

O Brasil é um importante produtor de milho, que a partir de meados da década de 1970 sofreu mudanças em termos de produção, produtividade e área, principalmente nos cenários das regiões produtoras da commodity. $\mathrm{O}$ aumento da área e o desenvolvimento de inovações (desenvolvimento da modernização agrícola), nas diferentes etapas produtivas, possibilitaram consideráveis incrementos na produção. Além disso, a produção, que era predominantemente na região Sul, passou a concentrar-se também no Centro-Oeste, tendo o Estado do Mato Grosso como o maior produtor.

Apesar da produtividade nacional apresentar resultados menos expressivos, se comparada com os principais países produtores de milho, seus resultados crescentes estão tornando o milho brasileiro cada vez mais competitivo - mesmo considerando a instabilidade da produtividade ao longo dos anos. A partir desse incremento, os Estados do Sul, do Sudeste e do Centro-Oeste (sendo exceção o Mato Grosso do Sul), apresentaram as maiores produtividades do grão, obtendo resultados superiores a $6.000 \mathrm{~kg} \mathrm{ha}^{-1}$ na safra 2016/17.

As mudanças no cenário produtivo do milho brasileiro ocorreram por meio da combinação de fatores, como: (a) expansão da área destinada à cultura; (b) desenvolvimento e adoção de tecnologias; e (c) práticas de manejo que proporcionam maior nível de respostas produtivas. Além disso, sugere-se a busca de medidas que potencializem a eficiência produtiva em regiões que não apresentaram rendimentos compatíveis com o seu potencial produtivo.

\section{REFERÊNCIAS}

ALBUQUERQUE, A. W.; SANTOS, J. R.; REIS, L. S. Plantas de cobertura e adubação nitrogenada na produção de milho em sistema de plantio direto. Revista Brasileira de Engenharia Agrícola e Ambiental-Agriambi, v. 17, n. 7, p. 721-726, 2013.

ALMEIDA, A. M. M.; MENDES FILHO, P. F.; GARCIA, K. G. V.; GOMES, V. F. F.; ALMEIDA, C. L. Densidade, caracterização e eficiência de bactérias fixadoras de Nitrogênio em áreas de caatinga degradada. Revista Verde de Agroecologia e Desenvolvi- 
mento Sustentável, v. 13, n. 1, p. 16-21, 2018.

ALVES, H. C. R.; AMARAL, R. F. Produção, área colhida e produtividade do milho no Nordeste. Banco do Nordeste. Fortaleza: Informe Rural Etene, 2011.

ARAUS, J. L.; SERRET, M. D.; EDMEADES, G. Phenotyping maize for adaptation to drought. Frontiers in physiology, v. 3, p. 305, 2012.

ARTUZO, F. D. Análise da eficiência técnica e econômica da agricultura de precisão a taxa variável de fertilizantes na cultura da soja no RS. 113 f. Dissertação (Mestrado-Agronegócios). Universidade Federal do Rio Grande do Sul, Porto Alegre, 2015.

ARTUZO, F. D.; FOGUESATTO, C. R.; SILVA, L. X. Agricultura de precisão: inovação para a produção mundial de alimentos e otimização de insumos agrícolas. Revista Tecnologia e Sociedade, v. 13, n. 29, p. 146-161, 2017.

ASSEFA, T.; MEUWISSEN, M.; LANSINK, A.; OUDE, J. M. G. Price risk perceptions and management strategies in selected European food supply chains: An exploratory approach. NJAS-Wageningen Journal of Life Sciences, v. 80, p. 15-26, 2017.

ÁVILA, D. F.; GRIEBELER, M. P. D.; BRUM, A. L. Inovação: a Modernização da Agricultura no Planalto Gaúcho (Brasil). UNOPAR Científica Ciências Jurídicas e Empresariais, v. 16, n. 2, p. 156-164, 2015.

BERGAMASCHI, H.; DALMAGO, G. A.; BERGONCI, J. I.; BIANCHI, C. A. M.; MÜLLER, A. G.; COMIRAN, F.; HECKLER, B. M. M. Distribuição hídrica no período crítico do milho e produção de grãos. Pesquisa Agropecuária Brasileira, v. 39, n. 9, p. 831839, 2004.

CALDARELLI, C. E.; BACCHI, M. R. P. Fatores de influência no preço do milho no Brasil. Nova Economia, v. 22, n. 1, p. 141-164, 2012.

COELHO, A. M.; CRUZ, J. C.; PEREIRA, F. I. A. Rendimento do milho no Brasil: chega- 
mos ao máximo. Informações Agronômicas, v. 101, p. 1-12, 2003. Encarte técnico.

CONAB - COMPANHIA NACIONAL DE ABASTECIMENTO. Séries históricas. 2018. Disponivel em: < https://portaldeinformacoes.conab.gov.br/index.php/safra-serie-historica-dashboard > . Acesso em: 27 abr. 2018.

COOPER, D. R.; SCHINDLER, P. S. Métodos de pesquisa em administração. $7^{\mathrm{a}}$ ed. Porto Alegre: Bookman, 2003.

EMBRAPA - EMPRESA BRASILEIRA DE PESQUISA AGROPECUÁRIA. Cultivo do milho: clima e solo. Embrapa Milho e Sorgo. Comunicado técnico, 2002.

EMBRAPA - EMPRESA BRASILEIRA DE PESQUISA AGROPECUÁRIA. Sistema brasileiro de classificação de solos. Centro Nacional de Pesquisa de Solos: Rio de Janeiro, 2013.

FAVRO, J.; CARAVIERI, A. M. M.; MARCONATO, M.; NASCIMENTO, S. P.; CAMARA, M. R. G.; CALDARELLI, E. Análise da Evolução da Produtividade do Milho em Estados Selecionados no Brasil nos Anos de 2001 e 2011. Economia e Região, v. 3, n. 2, p. $25-45,2015$.

FAOSTAT - FOOD AGRICULTURE ORGANIZATION OF THE UNITED NATIONS. COMparação de dados. Produção. 2017. Disponível em: <www.fao.org/faostat/en/\#data >. Acesso em: 01 mai. 2018.

GARCIA, J. C.; MATTOSO, M. J.; DUARTE, J. O. Importância do milho em Minas Gerais. Informe Agropecuário, Belo Horizonte, v. 27, n. 233, p. 7-12, 2006.

GASQUES, J. G.; BASTOS, E. T.; VALDES, C.; BACCHI, M. R. P. Produtividade da agricultura brasileira e os efeitos de algumas políticas. Revista de Política Agrícola, v. 21, n. 3, p. 83-92, 2012.

GASQUES, J. G.; BASTOS, E. T.; VALDES, C.; BACCHI, M. R. P. Produtividade da agricultura: reSultado para o Brasil e estados selecionados. Revista de Política Agrícola, v. 23, n. 3, p. 87-98, 2014. 
GOMES, M. S.; VON PINHO, R. G.; OLIVEIRA, J. S.; VIANA, A. C. Avaliação de cultivares de milho para a produção de silagem: parâmetros genéticos e interação genótipos por ambientes. In: Congresso Brasileiro de Melhoramento de Plantas. Anais... Goiânia, 2002.

GONG, F.; WU, X.; ZHANG, H.; CHEN, Y.; WANG, W. Making better maize plants for sustainable grain production in a changing climate. Frontiers in Plant Science, v. 6,835 .

IBGE - INSTITUTO BRASILEIRO DE GEOGRAFIA E ESTTÍ́STICA. Mapas de Bioma e de Vegetação. 2004. Disponível em: < http://www.ibge.gov.br/home/presidencia/ noticias/21052004biomashtml.shtm > . Acesso em: 28 abr. 2016.

IMEA - INSTITUTO MATOGROSSENSE DE ECONOMIA AGROPECUÁRIO. Entendendo o mercado do milho. 2015. Disponível em: < http://www.imea.com.br/upload/ pdf/arquivos/Paper_jornalistas_Milho_AO.pdf>. Acesso em: 29 fev. 2016.

KANEKO, F. H.; HERNANDEZ, F. B. T.; SHIMADA, M. M.; FERREIRA, J. P. Estudo de caso-Análise econômica da fertirrigação e adubação tratorizada em pivos centrais considerando a cultura do milho. Agrarian, v. 5, n. 16, p. 161-165, 2012.

KÖPPEN, W. Classificação de Köppen: significado dos símbolos e critérios para classificações. In: VIANELLO, R. L.; ALVES, A. R. Meteorologia básica e aplicações. Viçosa: Editora da UFV, 2004. 449 p.

LANGEMEIER, M.; LUNIK, E. International Benchmarks for Corn Production. Purdue Agriculture Center for Commercial Agriculture, June 2015. Disponível em: $<$ ag.purdue.edu/commercialag/Pages/Resources/Management-Strategy/International-Benchmarks/International-Benchmarks-Corn.aspx > . Acesso em: 15 mar. 2016.

MANZATTO, C. V.; FREITAS JUNIOR, E.; PERES, J. R. R. Uso agrícola dos solos brasileiros. Embrapa, 2002.

MATOS, P. F.; PESSÔA, V. L. S. A modernização da agricultura no Brasil e os novos usos do território. GeoUerj, v. 2, n. 22, p. 290-322, 2011. 
MAROUELLI, R. P. O desenvolvimento sustentável da agricultura no cerrado brasileiro. Brasília: ISAE FGV/Ecobusiness School, 2003.

MOLIN, J. P.; AMARAL, L. R.; COLAÇO, A. Agricultura de precisão. São Paulo: Oficina de Textos, 2015.

NABINGER, C.; FERREIRA, E. T.; FREITAS, A. K.; CARVALHO, P. C. F.; SANT'ANNA, D. M. Produção animal com base no campo nativo: aplicações de resultado de pesquisa. Campos Sulinos: conservação e uso sustentável da biodiversidade. Brasília: Ministério do Meio Ambiente, 2009.

NOGARA NETO, F.; ROLOFF, G.; DIECKOW, J.; MOTTA, A. C. V. Atributos de solo e cultura espacialmente distribuídos relacionados ao rendimento do milho. Revista Brasileira de Ciência do Solo, v. 35, n. 3, p. 1025-1036, 2011.

PATERNIANI, E. Agricultura sustentável nos trópicos. Estudos avançados, v. 15, n. 43, p. 303-326, 2001.

PEDROSO, I. L. P. B. Meio ambiente, agroindústria e ocupação dos cerrados: o caso do município do Rio Verde no sudoeste de Goiás. Revista Urutágua, v. 6, p. 1-10, 2004 .

PEEL, M. C.; FINLAYSON, B. L.; MCMAHON, T. A. Mapa do mundo atualizada do Köppen-Geiger Classificação climática. Hydrology and Earth System Sciences, v. 11, p. 1633-1644, 2007.

PONCIANO, N. J.; SOUZA, P. M.; REZENDE, A. M. Entraves da Comercialização à Competitividade do Milho Brasileiro. Revista Paranaense de Desenvolvimento, $\mathrm{n}$. 104, p. 23-40, 2003.

RELINGER, R. NAFTA and US cornsubsidies: Explaining the displacement of Mexico's corn farmers. Prospect Journal of International Affairs at UCSD, 2010. Disponível em: < prospectjournal.org. >. Acesso em: 09 mar. 2016.

SCHMITZ, T. G.; SCHMITZ, A.; MOSS, C. B. The economic impact of Star Link corn. 
Agribusiness, v. 21, n. 3, p. 391-407, 2005.

SOUZA, R. O.; TEIXEIRA, S. M. Produtividade Total dos Fatores na Agricultura Goiana: Uma Análise para as Culturas de Cana-de-açúcar, Milho e Soja. Revista de Economia e Agronegócio-REA, v. 11, n. 2, p. 211-234, 2015.

VALOIS, A. C. C. Importância dos transgênicos para a agricultura. Cadernos de Ciência e Tecnologia, v. 18, n. 1, p. 27-53, 2001.

VILLORIA, N. B.; CHEN, B. Yield risks in global maize markets: Historical evidence and projections in key regions of the world. Weather and Climate Extremes, v. 19, p. 42-48, 2018.

WILHELM, W. W.; WORTMANN, C. S. Tillage and rotation interactions for corn and soybean grain yield as affected by precipitation and air temperature. Agronomy Journal, v. 96, n. 2, p. 425-432, 2004.

YAN, W.; ZHONG, Y.; SHANGGUAN, Z. Evaluation of physiological traits of summer maize under drought stress. Acta Agricultura e Scandinavica, Section B - Soil \& Plant Science, v. 66, n. 2, p. 133-140, 2016.

ZINSELMEIER, C.; WESTGATE, W. E.; JONES, R. J. Kernel Set at Low Water Potential Does Not Vary with Source/Sink Ration in Maize. Crop Science, v. 35, n. 1, p. 158163, 1995.

Recebido em: 25/08/2016

Aceito em: 06/06/2018 